\title{
Bacterial programming of host responses: coordination between type I interferon and cell death
}

\section{Miqdad O. Dhariwala and Deborah M. Anderson*}

Department of Veterinary Pathobiology, University of Missouri, Columbia, MO, USA

\section{Edited by:}

Yoichi Furuya, Albany Medical College, USA

\section{Reviewed by:}

Adrianus Wilhelmus Maria Van Der Velden, Stony Brook University -

State University of New York, USA

Dane Parker, Columbia University,

USA

Devender Kumar, University of

Calgary, Canada

*Correspondence:

Deborah M. Anderson, Department of Veterinary Pathobiology, University of Missouri, Columbia, MO 65211, USA e-mail: andersondeb@missouri.edu
During mammalian infection, bacteria induce cell death from an extracellular or intracellular niche that can protect or hurt the host. Data is accumulating that associate type I interferon (IFN) signaling activated by intracellular bacteria with programmed death of immune effector cells and enhanced virulence. Multiple pathways leading to IFN-dependent host cell death have been described, and in some cases it is becoming clear how these mechanisms contribute to virulence. Yet common mechanisms of IFN-enhanced bacterial pathogenesis are not obvious and no specific interferon stimulated genes have yet been identified that cause sensitivity to pathogen-induced cell death. In this review, we will summarize some bacterial infections caused by facultative intracellular pathogens and what is known about how type I IFN signaling may promote the replication of extracellular bacteria rather than stimulate protection. Each of these pathogens can survive phagocytosis but their intracellular life cycles are very different, they express distinct virulence factors and trigger different pathways of immune activation and crosstalk. These differences likely lead to widely varying amounts of type I IFN expression and a different inflammatory environment, but these may not be important to the pathologic effects on the host. Instead, each pathogen induces programmed cell death of key immune cells that have been sensitized by the activation of the type I IFN response. We will discuss how IFN-dependent host cell death may increase host susceptibility and try to understand common pathways of pathogenesis that lead to IFN-enhanced bacterial virulence.

Keywords: Yersinia, plague, Francisella, Salmonella, Listeria, type I interferon, cell death, bacterial infection

\section{INTRODUCTION}

Type I interferon (IFN) is a major component of the mammalian innate immune system, especially important for defense against viral infection (Stark et al., 1998). Nearly all cells in the body express the type I IFN receptor (IFNAR), making this potent antiviral response capable of protecting every type of cell. Against bacterial infection, type I IFN can activate inflammatory responses that protect the host, but can also lead to hyper-inflammatory responses and programmed cell death which can hurt the host (Decker et al., 2005). In addition, type I IFN induced during viral infection can lead to increased apoptosis of granulocytes which can prevent clearance of a super-infection caused by Grampositive or Gram-negative bacterial pathogens (Navarini et al., 2006).

Interferon- $\beta$ is typically induced following detection of pathogen associated molecular patterns (PAMPs) by membranebound or cytoplasmic pattern recognition receptors (PRRs; Takeuchi and Akira, 2010). Expression of type I IFN is regulated at the transcriptional level, with binding sites for multiple activators in Ifn promoters. Membrane or cytoplasmic PRRs in the host cell signal through adaptor proteins to activate interferon regulatory transcription factors (IRFs), such as IRF-1, 3, 5, or 7. Phosphorylated IRF migrates to the nucleus, and cooperates with NF- $\mathrm{kB}$ and other co-activators to form an enhanceosome that binds the Ifn $\beta$ promoter and activates transcription (Panne et al., 2007). Secreted IFN- $\beta$ binds to IFNAR which results in the activation of the JAK-STAT pathway leading to the formation of the interferon-stimulated gene factor 3 (ISGF3) complex (Ivashkiv and Donlin, 2014). This complex translocates to the nucleus and can initiate the transcription of interferon-stimulated genes (ISGs) via their $5^{\prime}$ enhancer elements known as Interferon Stimulated Response Elements (ISREs). These ISGs encode Ifn $\beta$, pro- and anti-inflammatory cytokines, activators or inhibitors of programmed cell death, and numerous anti-viral proteins (Sato etal., 1998; de Veer etal., 2001; Schoggins and Rice, 2011).

Nucleic acids, secondary messengers, cell wall, or membrane fragments from bacteria activate expression of IFN- $\beta$ following its detection by phagosomal or cytoplasmic PRRs (Takeuchi and Akira, 2010; Woodward et al., 2010; Jin et al., 2011a; Parvatiyar et al., 2012). Many pathogenic bacteria survive phagocytosis and may even grow in the intracellular compartment. When intracellular PRRs are activated, a downstream type I IFN response may include increased pro-inflammatory cytokine expression, down-regulation of cytokine receptors, or the sensitizing of key immune cells to undergo programmed cell death. Increasing evidence associates IFN-dependent host cell death during bacterial infection with increased susceptibility to disease. It is clear that the factors that determine the outcome of IFN signaling are complex and influenced by cell-and tissue-specific 
host-pathogen interactions. In this review, we will discuss type I IFN-dependent sensitization of immune cells to programmed cell death during bacterial infection, the host-pathogen interactions that might enhance this outcome and how it might contribute to disease.

\section{IFN-DEPENDENT DEPLETION OF IMMUNE EFFECTOR CELLS CRIPPLES HOST DEFENSE}

Yersinia pestis is a recently evolved vector borne pathogen that causes the lethal diseases bubonic, septicemic, and pneumonic plague (Pollitzer, 1954). All three forms lead to systemic disease and after the infection eliminates virtually all of the phagocytic cells, extracellular bacterial growth is uncontrolled (Heine et al., 2013). When mammals, including humans, inhale Y. pestis aerosols, primary pneumonic plague develops in a short period, resulting in a deadly bronchopneumonia that becomes untreatable shortly after symptoms present (Butler, 2013). Neutrophil recruitment and function is critical for host defense against $Y$. pestis infection as well as antibody-mediated protection (Laws et al., 2010; Eisele et al., 2011).

Evasion of the innate immune system by $Y$. pestis is driven by two dominant virulence mechanisms: tetraacylated LPS and a type 3 secretion system (T3SS). Thermal control of acetylases causes hypoacetylation of lipid A at the mammalian body temperature resulting in predominantly the tetraacylated form during infection (Kawahara et al., 2002; Rebeil et al., 2006). Tetraacylated LPS does not stimulate toll-like receptor 4 (TLR-4) and may have antiinflammatory properties that limit the activation of immune cells by extracellular bacteria (Montminy et al., 2006; Valdimer et al., 2012).

Upon intimate contact with a host cell, the T3SS spans the inner and outer membranes and a translocation pore is formed in the host cell plasma membrane but detection of this pore by the host inflammasome is blocked by the bacterial protein YopK (Cornelis, 2006; Brodsky et al., 2010). YopK is one of seven effector proteins of the T3SS, collectively referred to as Yersinia Outer Proteins (Yops), that are transported into the cytoplasm of the host cell where their combined action disrupts signaling pathways, reduces phagocytosis, halts the expression of pro-inflammatory cytokines, and induces programmed cell death through multiple mechanisms (Raymond et al., 2013). This action stalls the inflammatory response, creating an anti-inflammatory environment that is permissive for bacterial growth (Price et al., 2012). Substantial evidence suggests that extracellular bacteria preferentially target macrophages and neutrophils and cause their depletion as the infection progresses (Marketon et al., 2005; Maldonado-Arocho et al., 2013; Pechous et al., 2013).

YopJ is a T3SS effector protein with deubiquitinase and acetylase activity that prevents activation of NF- $\kappa \mathrm{B}$, MAP kinase kinase, and IRF-3, as well as other proteins in the host causing suppression of pro-inflammatory cytokine expression (Monack et al., 1997; Palmer et al., 1998; Orth et al., 1999; Zhou et al., 2005; Sweet et al., 2007). Suppression of NF- $\kappa$ B and activation of RIP1 by YopJ leads to the initiation of apoptosis and pyroptosis, respectively (Monack et al., 1997; Zheng et al., 2011; Philip et al., 2014). The amount of YopJ injected, host cell type and the action of other Yops such as YopK influence the amount of cell death that is caused by YopJ and, although it appears that evolution is favoring reduced secretion of YopJ, this protein and its proper regulation are important to Yersinia virulence (Holmstrom et al., 1995; Lemaitre et al., 2006; Brodsky and Medzhitov, 2008; Zauberman et al., 2009; Brodsky et al., 2010; Peters et al., 2013).

The combined evasion provided by YopJ and the tetraacylated lipid A leads to immune suppression that delays neutrophil recruitment allowing for establishment of bacterial colonies in susceptible tissues. Type I IFN expression can be detected early during infection when other pro-inflammatory cytokines are suppressed (Patel et al., 2012). Nevertheless, the absence of type I IFN signaling does not alter the expression of pro-inflammatory cytokines including those harboring ISREs. Overall the data suggest that the immune suppressive environment established during the early stages of $Y$. pestis infection does not prevent expression of IFN- $\beta$ but nevertheless, at least some ISGs are suppressed.

If a macrophage succeeds in taking up $Y$. pestis before it is injected by the T3SS, the bacteria can remain viable inside a membrane-enclosed compartment known as the Yersinia containing vacuole (YCV) where the T3SS functions poorly (Zhang et al., 2011). Intracellular survival requires bacterial stress response pathways which presumably allow the bacteria to adjust to an adverse, nutrient-limiting environment (Oyston et al., 2000; Grabenstein et al., 2004). Intracellular Y. pestis eventually lyse the cell and once extracellular, the bacteria appear to have acquired increased resistance to phagocytosis and killing by neutrophils (Ke et al., 2013). Y. pestis mutants that are unable to survive in activated macrophages were less virulent in murine plague models suggesting the intracellular life cycle is a biologically relevant process that contributes to the success of infection (Oyston et al., 2000).

Host pathogen interactions that occur as a result of the intracellular life cycle of Yersinia are largely uncharacterized. Although extracellular bacteria effectively suppress the expression of pro-inflammatory cytokines, the host likely detects intracellular Y. pestis where an abundance of PRRs can bind nucleic acids as well as surface located PAMPs and, to date, no microbial species have been described that escape detection inside host cells. Recently, expression of the mitochondrial-located adaptor protein MAVS was identified as induced by $Y$. pestis infection of macrophages (Du et al., 2014). Mice lacking MAVS were more resistant to $Y$. pestis infection, suggesting that MAVS could play a role in inducing type I IFN. Together the data support the likelihood that one or more intracellular PRRs are activated by Yersinia, causing expression of IFN- $\beta$.

Pulmonary infection of mice by $Y$. pestis leads to neutropenia that becomes pronounced as the infection progresses (Patel et al., 2012). Mice lacking Ifnar were more resistant to lethal disease and this was associated with an increased population of neutrophils in the bone marrow and spleen without detectable changes to the inflammatory response. In contrast, Ifnar ${ }^{+/+}$mice had reduced populations of $\mathrm{Gr}-1^{+}$neutrophils in both primary and secondary immune tissues that became more pronounced as the infection progressed. These observations suggest that neutrophil migration is not impacted by type I IFN but more likely it has a direct effect on maturation or viability of this effector 
population (Figure 1). In vitro, $\mathrm{T}^{2} \mathrm{SS}^{+}$Yersinia caused similar levels of cytotoxicity of WT and Ifnar ${ }^{-/-}$bone marrow derived macrophages after $5.5 \mathrm{~h}$ infection. While this does not rule out the possibility that Yersinia infection directly causes IFN-dependent cell death through another mechanism, the data are consistent with an IFN-dependent depletion of neutrophils, perhaps by sensitizing them to undergo cell death in vivo.

Interferon-dependent sensitization of immune cells to programmed cell death was among the initial observations of pathology conferred by type I interferon during bacterial infections in the well-characterized model system of another facultative intracellular pathogen Listeria monocytogenes. We now know the details of a number of IFN-dependent host responses to L. monocytogenes, a pathogen with multiple mechanisms for inducing programmed cell death. Detection of Listeria by TLR-2 leads to expression of pro-inflammatory cytokines (McCaffrey et al., 2004; Torres et al., 2004). L. monocytogenes can escape this response by invading phagocytic and non-phagocytic cells where it escapes from intracellular vacuoles and grows in the cytoplasm. Detection of nucleotide secreted by bacteria in the cytoplasm is signaled through the adaptor protein STING which leads to the phosphorylation of IRF-3 and expression of IFN- $\beta$ (Burdette and Vance, 2013).

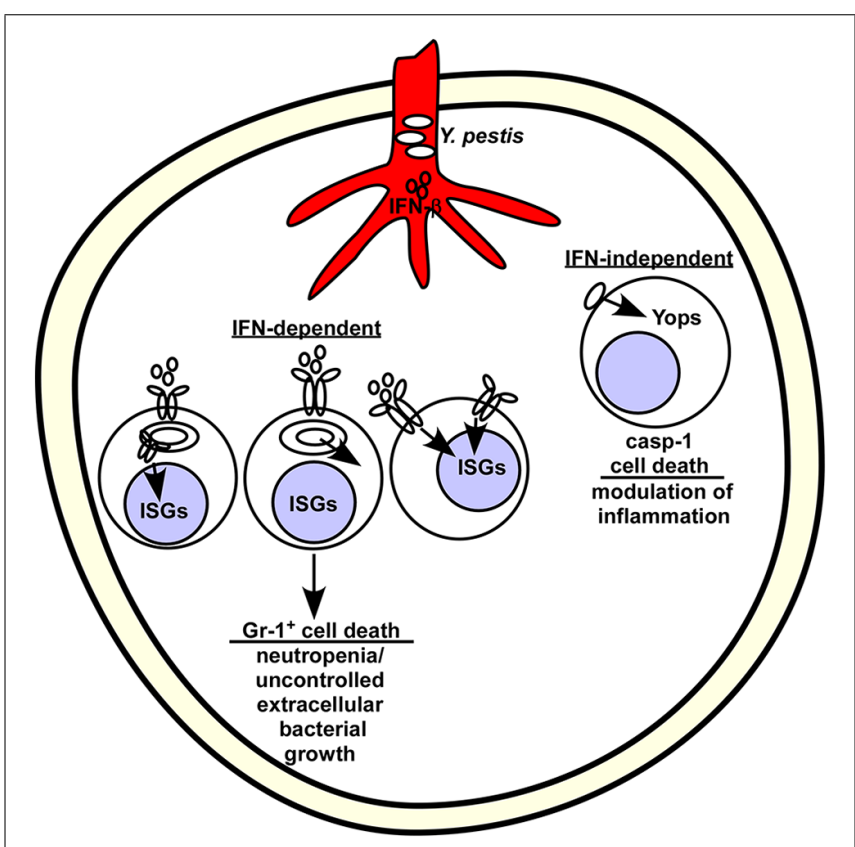

FIGURE 1 | Model for interferon (IFN)- $\beta$ stimulated depletion of neutrophils in the bone marrow following Yersinia pestis infection. $Y$. pestis stimulate IFN- $\beta$ production in the blood shortly after infection. Bacteria likely disseminate from the infection site through the vasculature, where they reach and colonize the bone marrow. Given their tropism for phagocytic cells, Yersinia might preferentially interact with $\mathrm{Gr}-1+$ cells, which are typically mature neutrophils and monocytes. Extracellular bacteria use the type III secretion system to inject Yops and stimulate caspase-1-dependent, IFN-independent cell death. Intracellular bacteria may stimulate host pathways that combine with IFN to activate cell death (left) or secrete a protein that activates IFN-dependent cell death (middle). Alternatively, the inflammatory signals received by $\mathrm{Gr}-1^{+}$cells may prevent their activation (not shown) or induce cell death (shown).
Multiple mechanisms are believed to contribute to the increased resistance of Ifnar ${ }^{-/-}$mice to L. monocytogenes infection (Auerbach et al., 2004; Carrero et al., 2004; O'Connell et al., 2004). IFNdependent susceptibility to infection correlated with increased apoptosis of splenic T cells, not necessarily infected by Listeria, which resulted in a reduction of IFN- $\gamma$ and an increase in IL-10 expression, both of which would suppress macrophage activation and bacterial killing. Further, $I l 10^{-/-}$mice were also more resistant to L. monocytogenes infection, supporting the model whereby IFN enhanced pathogenesis may be affected by changes in IL-10 (Carrero et al., 2006; Biswas et al., 2007). However, the mechanism whereby $\mathrm{T}$ cells become sensitized to apoptosis is not yet clear. Paradoxically, IFNAR signaling also causes up-regulation of CD69 in T cells which increased their sensitivity to antigenic stimulation during Listeria infection (Feng etal., 2005). Deletion of CD69 blocks protective immunity to Listeria even though $C d 69^{-/-}$mice produced increased levels of IFN- $\beta$ and this induced increased levels of T cell apoptosis (Vega-Ramos et al., 2010).

Listeriolysin O (LLO) is a toxin secreted by L. monocytogenes that can cause host cell death and is required for bacteria to escape the phagosome and induce type I IFN (Schnupf and Portnoy, 2007). IFN- $\beta$ sensitizes macrophages to undergo LLO-mediated necrosis, lowering the amount of toxin required to cause cell death in vitro (Zwaferink et al., 2008). As macrophages are important for bacterial clearance, this mechanism likely also contributes to disease progression. Thus at least two key immune cells, T cells and macrophages, are sensitized by IFN- $\beta$ signaling to induce programmed cell death thereby crippling host defense against Listeria infection. In addition, IFN-dependent down-regulation of the IFN- $\gamma$ receptor also decreases activation of infected macrophages, and since IFN- $\gamma$ is required for bacterial clearance, this likely also contributes to increased susceptibility (Rayamajhi et al., 2010). Overall multiple IFN-dependent changes, some of which involve programmed cell death, may contribute to increased susceptibility of mice to Listeria infection.

\section{IFN-DEPENDENT MODULATION OF INFLAMMASOME ACTIVATION}

Francisella tularensis causes tularemia, a disease that begins with a very low infectious dose entering via one of a number of routes including inhalation (Dennis et al., 2002; Foley and Nieto, 2010). Inhalation of aerosolized F. tularensis leads to bacterial evasion of inflammatory responses and efficient invasion of alveolar macrophages (Hall et al., 2008). Francisella escape the phagosome and replicate in the host cytosol, eventually lysing the macrophage. Extracellular bacteria replicate and disseminate systemically likely through the vasculature. Pneumonic tularemia manifests in humans as an interstitial pneumonia that can cause death due to systemic disease and multi-organ failure.

Evasion of innate immune responses by Francisella can be attributed to its invasion of host cells, combined with a noncanonical LPS and absence of flagella (Jones et al., 2011). Thus, even though extracellular bacteria are recognized by TLR-2, intracellular bacteria are only weakly immunostimulatory. Once inside macrophages, Francisella escape the phagosome and replicate in the cytoplasm, where they eventually cause host cell death. Type A 
Francisella strains, including those that cause disease in humans, carry a duplicated copy of a $30 \mathrm{~kb}$ high pathogenicity island that encodes a type 6 secretion system (T6SS) which is required for virulence in the mouse model (Broms et al., 2010; Bröms et al., 2011; Long etal., 2012). Escape from the phagosome, replication in the cytoplasm and host cell death all depend on the T6SS (Lindgren et al., 2013). Like Listeria, Francisella escape from the phagosome occurs prior to lysosomal fusion and is detected by host PRRs in the cytoplasm which signal through STING to the IRF-3-dependent expression of type I IFN (Jones et al., 2010).

Francisella tularensis mutants that are unable to escape the phagosome or that survive poorly in the cytoplasm induce increased expression of IFN- $\beta$ and increased cytotoxicity due to activation of pyroptosis in macrophages (Peng et al., 2011). Phagosomal escape of $F$. tularensis subspecies novicida ( $F$. novicida), a type A strain that is virulent in mice but avirulent in humans, and type I IFN signaling activate the absent in melanoma-2 (AIM-2) inflammasome, which leads to cleavage of pro-caspase-1, secretion of IL-1 $\beta$ and host cell death (Henry et al., 2007). F. novicida mutants that fail to escape the phagosome were attenuated in the mouse model, suggesting that intracellular survival is necessary for virulence. Similarly, the absence of caspase-1, AIM-2 or the inflammasome adaptor protein ASC all individually caused increased susceptibility to F. novicida suggesting that the inflammasome contributes to host defense (Fernandes-Alnemri et al., 2010; Pierini et al., 2013). Paradoxically, IFNAR is required to activate caspase1 during $F$. novicida infection in vitro, but Ifnar $^{-/}$- mice were more resistant to pulmonary infection by this strain. This could be explained by type II IFN activation of the inflammasome in vivo which has been observed as a compensatory mechanism in the absence of type I IFN. Therefore, in vivo, Ifnar ${ }^{-/-}$mice are likely not deficient in activating the inflammasome during $F$. novicida infection.

Inflammasome activation by Francisella varies depending on cell type as well as bacterial strain which complicate interpretation of the in vivo data. Human dendritic cells, for example, induced much less caspase-1 dependent inflammasome activation when infected by F. tularensis SchuS4, a type A Francisella strain that is fully virulent in humans and mice (Bosio et al., 2007; Ireland et al., 2013). Similar to $Y$. pestis infection, SchuS4 suppresses activation of TLRs and the expression of pro-inflammatory cytokines, but is not able to prevent expression of IFN- $\beta$ from human dendritic cells (Bauler etal., 2011). In addition, caspase-1 may not play a significant role in host defense against SchuS4 (Dotson et al., 2013). These data suggest that intracellular SchuS4 may escape host cells through a distinct, caspase-1-independent mechanism and the role of type I IFN during infection by this strain is not clear (Lindemann et al., 2011).

Like $Y$. pestis, virulence of F. novicida may be enhanced by IFN signaling, as Ifnar ${ }^{-/}$mice were more resistant to pulmonary infection (Henry etal., 2010). Larger populations of IL-17Aproducing $\gamma \delta$ T-cells were found in the spleens of infected Ifnar ${ }^{-/-}$ mice and this correlated with increased neutrophil recruitment and survival. In vitro, IFN- $\beta$ signaling caused a decrease in F. novicida-induced IL-17A expression by $\gamma \delta \mathrm{T}$-cells suggesting a direct effect of IFN- $\beta$ on these cells. However, this effect may not extend to the virulent Francisella strain SchuS4 which is not only resistant to neutrophil-mediated killing but neutrophils may even contribute to disease caused by this strain (Bosio et al., 2007; Schwartz et al., 2012). Although the role of IFN- $\beta$ during challenge of mice with $F$. tularensis SchuS4 has not yet been described, pulmonary challenge of Il17R $\alpha^{-/-}$mice by F. tularensis SchuS4 did not result in increased survival suggesting IL-17A may not play an important role in this model (Skyberg et al., 2013). It will be interesting to see whether $\gamma \delta$ T-cells produce IFN-dependent IL-17A during infection by SchuS4 or if this strain induces an alternative response to type I IFN.

\section{IFN-DEPENDENT ESCAPE FROM HOST CELLS}

Salmonella enterica is a gastrointestinal pathogen with many serotypes that cause a range of diseases including the lethal typhoid fever (Santos, 2014). S. enterica infection begins as an interaction with intestinal $\mathrm{M}$ cells and enterocytes which take up bacteria from the small intestine. The bacteria survive in a modified phagosome, also called the Salmonella containing vacuole (SCV), and intracellular survival is essential for virulence in the murine and calf models (Libby et al., 1997; García-del Portillo, 2001). Intracellular bacteria eventually cause host cell death, allowing the bacteria access to an extracellular replicative niche where it can grow rapidly. Host cell death appears to be induced by multiple virulence factors that are exported from the SCVs via the type III secretion systems. Occasionally, Salmonella gains access to the vasculature and disseminates systemically, resulting in sepsis and multi-organ failure.

Salmonella express multiple PAMPs that are recognized by the host, including LPS and flagellin that strongly stimulate TLR-4 and NLRC4, respectively, and induce the expression of type I

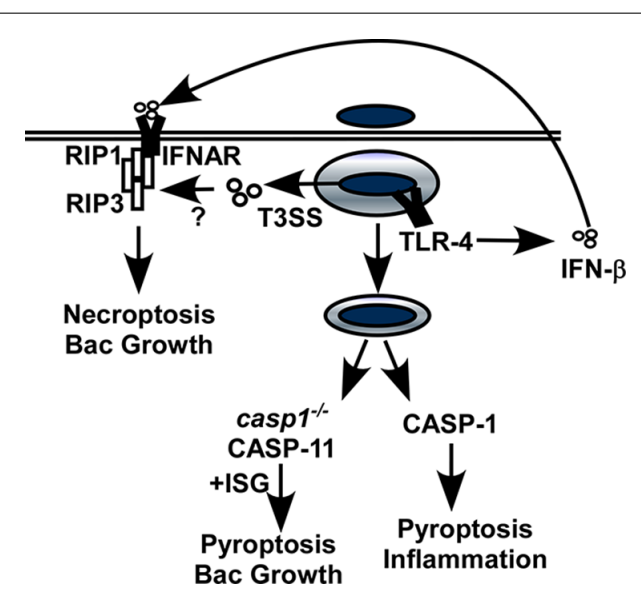

FIGURE 2 | Interferon-dependent and IFN-independent host cell death caused by Salmonella. Intracellular Salmonella remain in a vacuolar compartment where they undergo little, if any replication. The SPI-2 type III secretion system (T3SS) is required for intracellular survival, replication and host cell death. IFNAR promotes necroptosis by forming a complex with RIP1/RIP3, and may also activate the caspase-11 inflammasome under circumstances where caspase- 1 is absent. These two pathways favor bacterial replication, presumably because they provide an escape mechanism for the intracellular bacteria. In contrast, IFNAR-independent activation of caspase-1 leads to pyroptosis and inflammation and contributes to clearance of extracellular bacteria. 
Table 1 | Cell death and type I IFN during bacterial infection of macrophages.

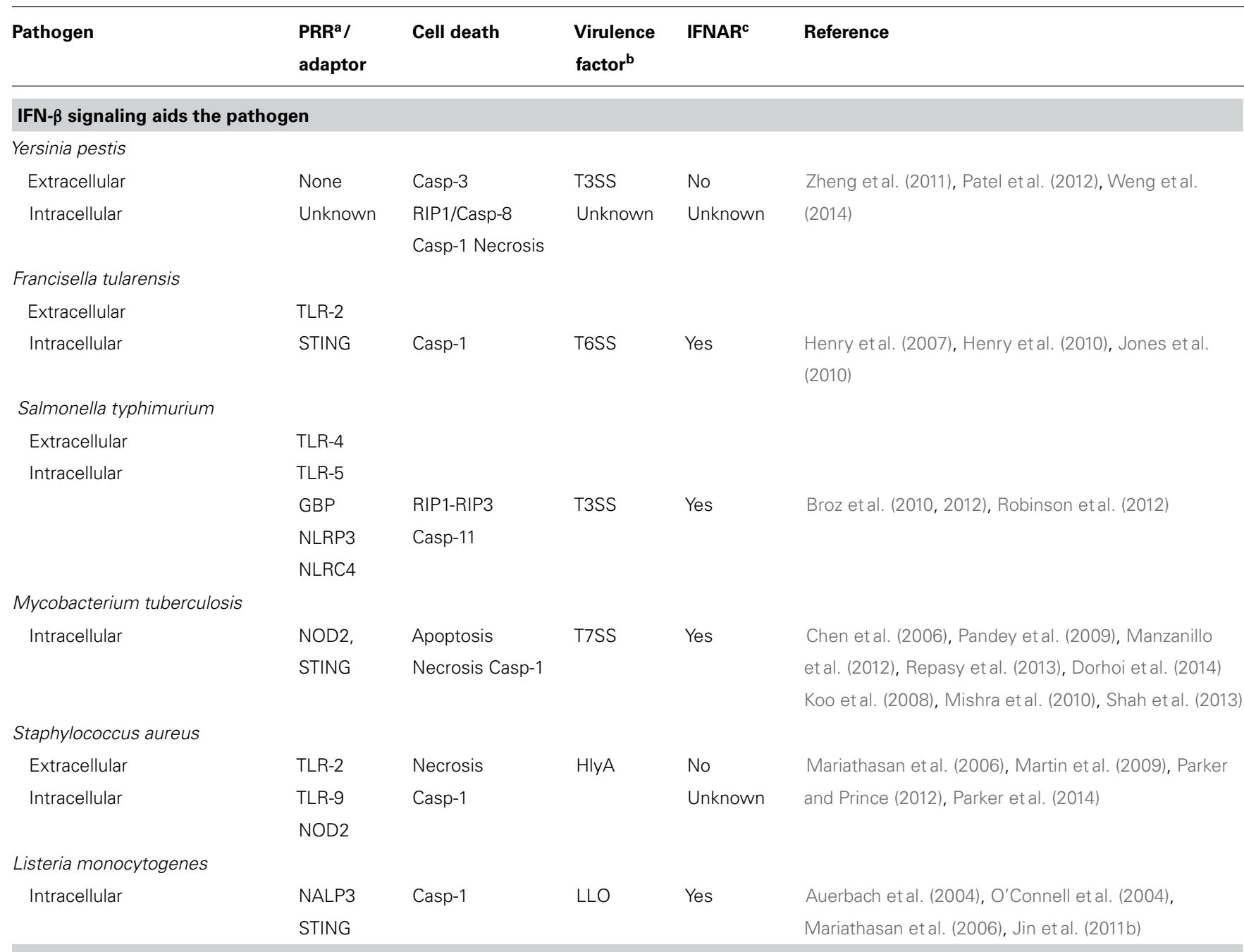

\section{IFN- $\beta$ signaling aids the host}

Legionella pneumophila

$\begin{array}{lll}\text { RIG-1 Casp-1 Unknown } & \text { Amer etal. (2006), Lightfield etal. (2008), Monroe } \\ \text { NLRC4 } & \text { et al. (2009), Nogueira et al. (2009), Plumlee et al. } \\ & \text { (2009), Lippmann etal. (2011) }\end{array}$

GroupB Streptococcus

TLR-7 None reported n/a Mancuso et al. (2009), Parker and Prince (2012)

Streptococcus pneumoniae

$\begin{array}{cl}\text { STING Necrosis } & \text { Ply Unknown } \quad \text { Weigent etal. (1986), Colino and Snapper (2003), } \\ \text { Apoptosis } & \text { N'Guessan etal. (2005), Sutterwala et al. (2007), } \\ & \text { Mancuso et al. (2009), Parker etal. (2011) }\end{array}$

Pseudomonas aeruginosa

\begin{tabular}{|c|c|c|c|c|}
\hline TLR-4 & Casp-3 & T3SS & Unknown & Faure etal. (2004), Power etal. (2007), Sutterwala \\
\hline NLRC4 & Casp-1 & Unknown & & etal. (2007), Carrigan etal. (2010), Parker et al. (2012) \\
\hline
\end{tabular}

a $P R R$, pattern recognition receptor.

bVirulence factor that stimulates cell death.

${ }^{\mathrm{C}}$ IFNAR = indicates if IFNAR is required for cell death. 
IFN (Wyant et al., 1999; Rosenberger et al., 2000). In addition, bacterial invasion of non-phagocytic cells results in the recognition of bacterial RNA by the cytosolic sensor RIG-I (Schmolke et al., 2014). Bacterial invasion of macrophages and epithelial cells requires the T3SS encoded on Salmonella Pathogenicity Island I (SPI-1; Fàbrega and Vilaa, 2013). Intracellular survival and replication require the T3SS encoded on SPI-2, which is also necessary for virulence in some models (Ochman et al., 1996; Libby et al., 1997; Winter et al., 2010). At least two SPI-2 effector proteins (SpvB and SseL) and one SPI-1 effector protein (SipB) are able to induce host cell death (Browne et al., 2002; Rytkonen et al., 2007). The cell death pathway induced by each of these proteins is distinct from one another, and each may provide an escape mechanism from the intracellular compartment.

Mice lacking Ifnar were more resistant to Salmonella infection with no detectable impact on the expression of pro-inflammatory cytokines (Robinson et al., 2012). Macrophages from Ifnar-/mice were resistant to Salmonella-induced cell death compared to macrophages from WT mice suggesting IFN signaling may activate host cell death (Figure 2). IFN- $\beta$ induced an interaction between IFNAR and RIP1 in infected cells which promoted RIP1/RIP3-dependent necroptosis. Like Ifnar ${ }^{-/-}$mice, Rip $^{-/-}$mice showed improved clearance of Salmonella infection suggesting this mechanism contributes to IFN-dependent pathogenesis. While these data provide a direct link between type I IFN, necroptosis and pathogenesis, there are additional mechanisms that are impacted by IFNAR during Salmonella infection.

Infection of stationary phase Salmonella leads to host cell death in vitro through a distinct mechanism involving the SPI-2 T3SS. Through this pathway, Salmonella induce the activation of the inflammasome which is enhanced by TLR-4-dependent type I IFN expression (Broz et al., 2012). Yet mice lacking inflammasome caspases 1 and 11 were more sensitive to infection suggesting that inflammasome activation is necessary for host defense against Salmonella. This apparent paradox is similar to the observations in the Francisella model and therefore may be explained by redundant activation of the inflammasome in vivo by type II IFN. Alternatively, specific cells or tissues may mediate susceptibility phenotypes or residual caspase-1 activation in the Ifnar ${ }^{-/}$mice is sufficient for host defense.

Casp $1^{-/-}$mice, which express caspase-11 and can activate the inflammasome, were more sensitive to infection than those lacking both caspases that were unable to induce inflammasome activation (Broz et al., 2012). This suggests that caspase-1 and caspase-11 contribute independent rather than redundant functions during infection and that caspase-11-induced cell death may increase disease susceptibility when caspase- 1 is absent. Increased resistance of $\operatorname{casp} 1^{+/+} / \operatorname{casp} 11^{-/-}$mice to multiple pathogens has been reported, including Francisella and there appears to be a connection with type I IFN signaling and caspase-11-mediated host pathology (Schroder and Tschopp, 2010). Activation of caspase-11 by Salmonella-infected macrophages was shown to be dependent on IFNAR, with a role for transcriptional activation of expression pro-caspase-11 as well as an additional function that is not well understood. Overall, these data suggest a second functional link between type I IFN and host cell death through the activation of pyroptosis during Salmonella infection. Together, it is clear that even for a single bacterial pathogen, type I IFN sensitizes cells through multiple mechanisms to induce programmed cell death. Escape from the host cell without a protective inflammatory response gives Salmonella the opportunity to grow rapidly and disseminate where it can cause severe disease.

\section{CONCLUDING REMARKS}

Studies of IFN-dependent host-pathogen interactions that lead to host cell death have been a focus for the last 10 years of research in bacterial pathogenesis, beginning with the initial observations in the Listeria model (Table 1). Bacterial secretion systems, often encoded within shared high pathogenicity islands, commonly induce type I IFN expression presumably because the secretion pore and/or the effector proteins are detected by cytoplasmic PRRs. The list of bacterial infections that benefit from IFN- $\beta$ signaling out-numbers those that are protected by it. Strikingly, the pathogens that benefit from IFN- $\beta$ signaling are all facultative intracellular bacteria.

Current sequencing technologies have revealed nearly 3,500 genes that are responsive to IFN- $\beta$ signaling, including transcription factors and regulators of programmed cell death (de Weerd et al., 2013). Confounding the ability to define ISGs that confer IFN-enhanced susceptibility to infection is the need to identify critical cells whose IFN-dependent response directly contributes to disease. Type I IFN expression specifically in myeloid cells has recently been shown to be critical to clearance of viral infection (Pinto etal., 2014). With the availability of mouse strains that restrict IFNAR expression to specific cells or tissues, it will be possible to study these issues in the bacterial infection models.

Multiple mechanisms of IFN-induced programmed cell death may contribute to bacterial infection in mouse models. There is beginning to be evidence that IFN-enhanced pathogenesis may also occur in humans. For example, virulence of Staphylococcus aureus isolated from human patients appears to correlate with increased production of type I IFN (Parker et al., 2014). Given the growing population of immunocompromised people and the confounding effects of co-infections often present in humans, particularly in hospitals, type I IFN may not always be a safe anti-viral treatment option in spite of its undisputed ability to stimulate clearance of viral infections. As we gain in our understanding of how IFN signaling combines with bacterial virulence factors to enhance disease, it may be possible to stimulate the anti-viral effects of type I IFN without placing the patient at risk for bacterial diseases.

\section{REFERENCES}

Amer, A., Franchi, L., Kanneganti, T. D., Body-Malapel, M., Ozoren, N., Brady, G., et al. (2006). Regulation of Legionella phagosome maturation and infection through flagellin and host Ipaf. J. Biol. Chem. 281, 35217-35223. doi: 10.1074/jbc.M604933200

Auerbuch, V., Brockstedt, D., Meyer-Morse, N., O'riordan, M., and Portnoy, D. (2004). Mice lacking the type I interferon receptor are resistant to Listeria monocytogenes. J. Exp. Med. 200, 527-533. doi: 10.1084/jem.20040976

Bauler, T., Chase, J., and Bosio, C. (2011). IFN- $\beta$ mediates suppression of IL-12p40 in human dendritic cells following infection with virulenr Francisella tularensis. J. Immunol. 187, 1845-1855. doi: 10.4049/jimmunol.1100377 
Biswas, P., Pedicord, V., Ploss, A., Menet, E., Leiner, I., and Pamer, E. (2007). Pathogen-specific CD8 T cell responses are directly inhibited by IL-10. J. Immunol. 179, 4520-4528. doi: 10.4049/jimmunol.179.7.4520

Bosio, C., Bielefeldt-Ohmann, H., and Belisle, J. (2007). Active suppression of the pulmonary immune response by Francisella tularensis Schu4. J. Immunol. 178.

Brodsky, I., and Medzhitov, R. (2008). Reduced secretion of YopJ by Yersinia limits in vivo cell death but enhances bacterial virulence. PLoS Pathog. 4:1-14. doi: 10.1371/journal.ppat.1000067

Brodsky, I., Palm, N., Sadanand, S., Ryndak, M., Sutterwala, F., Flavell, R., et al. (2010). A Yersinia effector protein promotes virulence by preventing inflammasome recognition of the type III secretion system. Cell Host Microbe 7, 376-387. doi: 10.1016/j.chom.2010.04.009

Bröms, J., Lavander, M., Meyer, L., and Sjöstedt, A. (2011). IglG and IglI of the Francisella pathogenicity island are important virulence determinants of Francisella tularensis LVS. Infect. Immun. 79, 3683-3696. doi: 10.1128/IAI.01344-10

Broms, J., Sjöstedt, A., and Lavander, M. (2010). The role of the Francisella tularensis pathogenicity island in type VI secretion, intracellular survival, and modulation of host cell signaling. Front. Microbiol. 1:136. doi: 10.3389/fmicb.2010.00136

Browne, S., Lesnick, M., and Guiney, D. (2002). Genetic requirements for Salmonella-induced cytopathology in human monocyte-derived macrophages. Infect. Immun. 70, 7126-7135. doi: 10.1128/IAI.70.12.7126-7135.2002

Broz, P., Newton, K., Lamkanfi, M., Mariathasan, S., Dixit, V., and Monack, D. (2010). Redundant roles for inflammasome receptors NLRP3 and NLRC4 in host defense against Salmonella. J. Exp. Med. 207, 1745-1755. doi: 10.1084/jem.20100257

Broz, P., Ruby, T., Belhocine, K., Bouley, D., Kayagaki, N., Dixit, V., et al. (2012). Caspase-11 increases susceptibility to Salmonella infection in the absence of caspase-1. Nature 490, 288-291. doi: 10.1038/nature11419

Burdette, D., and Vance, R. (2013). STING and the innate immune response to nucleic acids in the cytosol. Nat. Immunol. 14, 19-26. doi: 10.1038/ni.2491

Butler, T. (2013). Plague gives surprises in the first decade of the 21st century in the United States and worldwide. Am. J. Trop. Med. Hyg. 89, 788-793. doi: 10.4269/ajtmh.13-0191

Carrero, J., Calderon, B., and Unanue, E. (2004). Type I interferon sensitizes lymphocytes to apoptosis and reduces resistance to Listeria infection. J. Exp. Med. 200, 535-540. doi: 10.1084/jem.20040769

Carrero, J., and Calderon, B. U., and Unanue, E. R. (2006). Lymphocytes are detrimental during the early innate immune response against Listeria monocytogenes. J. Exp. Med. 203, 933-940. doi: 10.1084/jem.20060045

Carrigan, S., Junkins, R., Yang, Y., Macneil, A., Richardson, C., Johnston, B. et al. (2010). IFN regulatory factor 3 contributes to the host response during Pseudomonas aeruginosa lung infection in mice. J. Immunol. 185, 3602-3609. doi: 10.4049/jimmunol.0903429

Chen, M., Gan, H., and Remold, H. G. (2006). A mechanism of virulence: virulent Mycobacterium tuberculosis strain H37Rv, but not attenuated H37Ra, causes significant mitochondrial inner membrane disruption in macrophages leading to necrosis. J. Immunol. 176, 3707-3716. doi: 10.4049/jimmunol.176. 6.3707

Colino, J., and Snapper, C. M. (2003). Two distinct mechanisms for induction of dendritic cell apoptosis in response to intact Streptococcus pneumoniae. J. Immunol. 171, 2354-2365. doi: 10.4049/jimmunol.171.5.2354

Cornelis, G. (2006). The Type III injectisome. Nat. Rev. Microbiol. 4, 811-825. doi: $10.1038 /$ nrmicro 1526

de Veer, M., Holko, M., Frevel, M., Walker, E., Der, S., Paranjape, J., et al. (2001). Functional classification of interferon-stimulated genes identified using microarrays. J. Leuk. Biol. 69, 912-920.

de Weerd, N., Vivian, J., Nguyen, T., Mangan, N., Gould, J., Braniff, S., et al. (2013). Structural basis of a unique interferon-beta signaling axis mediated via the receptor IFNAR1. Nat. Immunol. 14, 901-907. doi: 10.1038/ ni.2667

Decker, T., Muller, M., and Stockinger, S. (2005). The yin and yang of type I interferon activity in bacterial infection. Nat. Rev. Immunol. 5, 675-687. doi: $10.1038 /$ nril684

Dennis, D., Inglesby, T., Henderson, D., Bartlett, J., Ascher, M., Eitzen, E., et al. (2002). Tularemia as a biological weapon. JAMA 285, 2763-2773. doi: 10.1001/jama.285.21.2763

Dorhoi, A., Yeremeev, V., Nouailles, G., Weiner, J., Jörg, S., Heinemann, E., et al. (2014). Type I IFN signaling triggers immunopathology in tuberculosis susceptible mice by modulating lung phagocyte dynamics. Eur. J. Immunol. 44, 2380-2393. doi: 10.1002/eji.201344219

Dotson, R., Rabadi, S., Westcott, E., Bradley, S., Catlett, S., Banik, S., et al. (2013). Repression of inflammasome by Francisella tularensis during early stages of infection. J. Biol. Chem. 288, 23844-23857. doi: 10.1074/jbc.M113.490086

Du, Z., Yang, H., Tan, Y., Tian, G., Zhang, Q., Cui, Y., et al. (2014). Transcriptomic response to Yersinia pestis: RIG-I like receptor signaling response is detrimental to the host against plague. J. Genet. Genomics 41, 379-396. doi: 10.1016/j.jgg.2014.05.006

Eisele, N., Lee-Lewis, H., Besch-Williford, C., Brown, C., and Anderson, D. (2011). Chemokine receptor CXCR2 mediates bacterial clearance rather than neutrophil recruitment in a murine model of pneumonic plague. Am. J. Pathol. 178, 11901200. doi: 10.1016/j.ajpath.2010.11.067

Fàbrega, A., and Vilaa, J. (2013). Salmonella enterica serovar typhimurium skills to succeed in the host: virulence and regulation. Clin. Microbiol. Rev. 26, 308-341. doi: 10.1128/CMR.00066-12

Faure, K., Sawa, T., Ajayi, T., Fujimoto, J., Moriyama, K., Shime, N., et al. (2004). TLR4 signaling is essential for survival in acute lung injury induced by virulent Pseudomonas aeruginosa secreting type III secretory toxins. Respir. Res. 5, 1. doi: 10.1186/1465-9921-5-1

Feng, H., Zhang, D., Palliser, D., Zhu, P., Cai, S., Schlesinger, A., et al. (2005). Listeriainfected myeloid dendritic cells produce IFN-beta, priming $\mathrm{T}$ cell activation. J. Immunol. 175, 421-432. doi: 10.4049/jimmunol.175.1.421

Fernandes-Alnemri, T., Yu, J., Juliana, C., Solorzano, L., Kang, S., Wu, J., et al. (2010). The AIM2 inflammasome is critical for innate immunity against Francisella tularensis. Nat. Immunol. 11, 385-393. doi: 10.1038/ni.1859

Foley, J. E., and Nieto, N. C. (2010). Tularemia. Vet. Microbiol. 140, 332-338. doi: 10.1016/j.vetmic.2009.07.017

García-del Portillo, F. (2001). Salmonella intracellular proliferation: where, when and how? Microbes Infect. 3, 1305-1311. doi: 10.1016/S1286-4579(01) 01491-5

Grabenstein, J., Marceau, M., Pujol, C., Simonet, M., and Bliska, J. (2004). The response regulator PhoP of Yersinia pseudotubeculosis is important for replication in macrophages and for virulence. Infect. Immun. 72, 4973-4984. doi: 10.1128/IAI.72.9.4973-4984.2004

Hall, J., Woolard, M., Gunn, B., Craven, R., Taft-Benz, S., Frelinger, J., et al. (2008) Infected-host-cell repertoire and cellular response in the lung following inhalation of Francisella tularensis SchuS4, LVS, or U112. Infect. Immun. 76, 5843-5852. doi: 10.1128/IAI.01176-08

Heine, H., Chuvala, L., Riggins, R., Hurteau, G., Cirz, R., Cass, R., et al. (2013). Natural history of Yersinia pestis pneumonia in aerosol-challenged BALB/c mice. Antimicrob. Agents Chemother. 57, 2010-2015. doi: 10.1128/AAC.02504-12

Henry, T., Brotcke, A., Weiss, D., Thompson, L., and Monack, D. (2007). Type I interferon signaling is required for activation of the inflammasome during Francisella infection. J. Exp. Med. 204, 987-994. doi: 10.1084/jem.20062665

Henry, T., Kirimanjeswara, G., Ruby, T., Jones, J., Peng, K., Perret, M., et al. (2010). Type I IFN signaling constrains IL-17A/F secretion by gamma-delta T cells during bacterial infections. J. Immunol. 184, 3755-3767. doi: 10.4049/jimmunol.0902065

Holmstrom, A., Rosqvist, R., Wolf-Watz, H., and Forsberg, A. (1995). Virulence plasmid-encoded YopK is essential for Yersinia pseudotuberculosis to cause systemic infection in mice. Infect. Immun. 63, 2269-2276.

Ireland, R., Wang, R., Alinger, J., Small, P., and Bosio, C. (2013). Francisella tularensis SchuS4 and SchuS4 lipids inhibit IL-12p40 in primary human dendritic cells by inhibition of IRF1 and IRF8. J. Immunol. 191, 1276-1286. doi: 10.4049/jimmunol.1300867

Ivashkiv, L., and Donlin, L. (2014). Regulation of type I interferon responses. Nat. Rev. Immunol. 14, 36-49. doi: 10.1038/nri3581

Jin, L., Hill, K., Filak, H., Mogan, J., Knowles, H., Zhang, B., et al. (2011a). MPYS is required for IFN response factor 3 activation and type I IFN production in the response of cultured phagocytes to bacterial second messengers cyclic-diAMP and cyclic-di-GMP. J. Immunol. 187, 2595-2601. doi: 10.4049/jimmunol. 1100088

Jin, L., Hill, K. K., Filak, H., Mogan, J., Knowles, H., Zhang, B., et al. (2011b). MPYS is required for IFN response factor 3 activation and type I IFN production in the response of cultured phagocytes to bacterial second messengers cyclic-di-AMP and cyclic-di-GMP. J. Immunol. 187, 2595-2601. doi: 10.4049/jimmunol.1100088 Jones, J., Kayagaki, N., Broz, P., Henry, T., Newton, K., O’rourke, K., et al. (2010). Absent in melanoma 2 is required for innate immune recognition 
of Francisella tularensis. Proc. Natl. Acad. Sci. U.S.A. 107, 9771-9776. doi: 10.1073/pnas.1003738107

Jones, J. V. V., Broz, P., and Monack, D. M. (2011). Innate immune recognition of Francisella tularensis: activation of type-I interferons and the inflammasome. Front. Microbiol. 2:16. doi: 10.3389/fmicb.2011.00016

Kawahara, K., Tsukano, H., Watanabe, H., Lindner, B., and Matsuura, M. (2002). Modification of the structure and activity of lipid A in Yersinia pestis lipopolysaccharide by growth temperature. Infect. Immun. 70, 4092-4098. doi: 10.1128/IAI.70.8.4092-4098.2002

Ke, Y., Chen, Z., and Yang, R. (2013). Yersinia pestis: mechanisms of entry into and resistance to the host cell. Front. Cell. Infect. Microbiol. 3:106. doi: 10.3389/fcimb.2013.00106

Koo, I. C., Wang, C., Raghavan, S., Morisaki, J. H., Cox, J. S., and Brown, E. J. (2008). ESX-1-dependent cytolysis in lysosome secretion and inflammasome activation during mycobacterial infection. Cell. Microbiol. 10, 1866-1878. doi: 10.1111/j.1462-5822.2008.01177.x

Laws, T., Davey, M., Titball, R., and Lukaszewski, R. (2010). Neutrophils are important in early control of lung infection by Yersinia pestis. Microbes Infect. 12, 331-335. doi: 10.1016/j.micinf.2010.01.007

Lemaitre, N., Sebbane, F., Long, D., and Hinnebusch, B. (2006). Yersinia pestis YopJ suppresses tumor necrosis factor alpha induction and contributes to apoptosis of immune cells in the lymph node but is not required for virulence in a rat mode of bubonic plague. Infect. Immun. 74, 5126-5131. doi: 10.1128/IAI.00219-06

Libby, S., Adams, L., Ficht, T., Allen, C., Whitford, H., Buchmeier, N., et al. (1997). The spv genes on the Salmonella dublin virulence plasmid are required for severe enteritis and systemic infection in the natural host. Infect. Immun. 65, 1786-1792.

Lightfield, K. L., Persson, J., Brubaker, S. W., Witte, C. E., Von Moltke, J., Dunipace, E. A., et al. (2008). Critical function for Naip5 in inflammasome activation by a conserved carboxy-terminal domain of flagellin. Nat. Immunol. 9, 1171-1178. doi: 10.1038/ni.1646

Lindemann, S., Peng, K., Long, M., Hunt, J., Apicella, M., Monack, D., et al. (2011). Francisella tularensis SchuS4 O-antigen and capsule biosynthesis gene mutants induce early cell death in human macrophages. Infect. Immun. 79, 581-594. doi: 10.1128/IAI.00863-10

Lindgren, M., Eneslätt, K., Bröms, J., and Sjöstedt, A. (2013). Importance of PdpC, IglC, IglI, and IglG for modulation of a host cell death pathway induced by Francisella tularensis. Infect. Immun. 81, 2076-2084. doi: 10.1128/IAI.00275-13

Lippmann, J., Muller, H. C., Naujoks, J., Tabeling, C., Shin, S., Witzenrath, M., etal. (2011). Dissection of a type I interferon pathway in controlling bacterial intracellular infection in mice. Cell. Microbiol. 13, 1668-1682. doi: 10.1111/j.1462-5822.2011.01646.x

Long, M., Lindemann, S., Rasmussen, J., Jones, B., and Allen, L. (2012). Disruption of Francisella tularensis Schu S4 iglI, iglJ, and pdpC genes results in attenuation for growth in human macrophages and in vivo virulence in mice and reveals a unique phenotype for pdpC. Infect. Immun. 81, 850-861. doi: 10.1128/IAI.00822-12

Maldonado-Arocho, F., Green, C., Fisher, M., Paczosa, M., and Mecsas, J. (2013). Adhesins and host serum factors drive Yop translocation by Yersinia into professional phagocytes during animal infection. PLoS Pathog. 9:e1003415. doi: 10.1371/journal.ppat.1003415

Mancuso, G., Gambuzza, M., Midiri, A., Biondo, C., Papasergi, S., Akira, S., et al. (2009). Bacterial recognition by TLR7 in the lysosomes of conventional dendritic cells. Nat. Immunol. 10, 587-594. doi: 10.1038/ni.1733

Manzanillo, P. S., Shiloh, M. U., Portnoy, D. A., and Cox, J. S. (2012). Mycobacterium tuberculosis activates the DNA-dependent cytosolic surveillance pathway within macrophages. Cell Host Microbe 11, 469-480. doi: 10.1016/j.chom.2012.03.007

Mariathasan, S., Weiss, D. S., Newton, K., Mcbride, J., O’rourke, K., Roose-Girma, M., et al. (2006). Cryopyrin activates the inflammasome in response to toxins and ATP. Nature 440, 228-232. doi: 10.1038/nature04515

Marketon, M., Depaolo, R., Debord, K., Jabri, B., and Schneewind, O. (2005). Plague bacteria target immune cells during infection. Science 309, 1739-1741. doi: 10.1126/science. 1114580

Martin, F., Gomez, M., Wetzel, D., Memmi, G., O'seaghdha, M., Soong, G., et al. (2009). Staphyloccus aureus activates type I IFN signaling in mice and humans through the Xr repeated sequences of protein A. J. Clin. Invest. 119, 1931-1939.

McCaffrey, R., Fawcett, P., O'riordan, M., Lee, K., Havell, E., Brown, P., et al. (2004). A specific gene expression program triggered by Gram-positive bacteria in the cytosol. Proc. Natl. Acad. Sci. U.S.A. 101, 11386-11391. doi: 10.1073/pnas.0403215101
Mishra, B. B., Moura-Alves, P., Sonawane, A., Hacohen, N., Griffiths, G., Moita, L. F., et al. (2010). Mycobacterium tuberculosis protein ESAT-6 is a potent activator of the NLRP3/ASC inflammasome. Cell. Microbiol. 12, 1046-1063. doi: 10.1111/j.1462-5822.2010.01450.x

Monack, D., Mecsas, J., Ghori, N., and Falkow, S. (1997). Yersinia signals macrophages to undergo apoptosis and YopJ is necessary for this cell death. Proc. Natl. Acad. Sci. U.S.A. 94, 10385-10390. doi: 10.1073/pnas.94.19.10385

Monroe, K., Mcwhirter, S., and Vance, R. (2009). Identification of host cytosolic sensors and bacterila factors regulating the type I interferon response to Legionella pneumophilea. PLoS Pathog. 5:e1000665. doi: 10.1371/journal.ppat.1000665

Montminy, S., Khan, N., Mcgrath, S., Walkowicz, M., Sharp, F., Conlon, J., et al. (2006). Virulence factors of Yersinia pestis are overcome by a strong lipopolysaccharide response. Nat. Immunol. 7, 1066-1073. doi: 10.1038/ ni1386

N'Guessan, P. D., Schmeck, B., Ayim, A., Hocke, A. C., Brell, B., Hammerschmidt, S., et al. (2005). Streptococcus pneumoniae R6x induced p38 MAPK and JNK-mediated caspase-dependent apoptosis in human endothelial cells. Thromb. Haemost. 94, 295-303.

Navarini, A., Recher, M., Lang, K., Georgiev, P., Meury, S., Bergthaler, A., et al. (2006). Increased susceptibility to bacterial superinfection as a consequence of innate antiviral responses. Proc. Natl. Acad. Sci. U.S.A. 103, 15535-15539. doi: 10.1073/pnas.0607325103

Nogueira, C. V., Lindsten, T., Jamieson, A. M., Case, C. L., Shin, S., Thompson, C. B., et al. (2009). Rapid pathogen-induced apoptosis: a mechanism used by dendritic cells to limit intracellular replication of Legionella pneumophila. PLoS Pathog. 5:e1000478. doi: 10.1371/journal.ppat.100047

O’Connell, R., Saha, S., Vaidya, S., Bruhn, K., Miranda, G., Zarnegar, B., et al. (2004). Type I interferon production enhances susceptibility to Listeria monocytogenes infection. J. Exp. Med. 200, 437-445. doi: 10.1084/jem.20040712

Ochman, H., Soncini, F., Solomon, F., and Groisman, E. (1996). Identification of a pathogenicity island required for Salmonella survival in host cells. Proc. Natl. Acad. Sci. U.S.A. 93, 7800-7804. doi: 10.1073/pnas.93.15.7800

Orth, K., Palmer, L., Bao, Z., Stewart, S., Rudolph, A., Bliska, J., et al. (1999). Inhibition of the mitogen-activated protein kinase kinase superfamily by a Yersinia effector. Science 285, 1920-1923. doi: 10.1126/science.285.5435.1920

Oyston, P., Dorrell, N., Williams, K., Shu-Rui, L., Green, M., Titball, R., et al. (2000). The response regulator PhoP is important for survival under conditions of macrophage-induced stress and virulence in Yersinia pestis. Infect. Immun. 68, 3419-3425. doi: 10.1128/IAI.68.6.3419-3425.2000

Palmer, L. E., Hobbie, S., Galan, J. E., and Bliska, J. B. (1998). YopJ of Yersinia pseudotuberculosis is required for the inhibition of macrophage TNF-alpha production and downregulation of the MAP kinases p38 and JNK. Mol. Microbiol. 27, 953-965. doi: 10.1046/j.1365-2958.1998.00740.x

Pandey, A., Yang, Y., Jiang, Z., Fortune, S., Coulombe, F., Behr, M., et al. (2009). NOD2, RIP2, and IRF5 play a critical role in the type I interferon response to Mycobacterium tuberculosis. PLoS Pathog. 5:e1000500. doi: 10.1371/journal.ppat.1000500

Panne, D., Maniatis, T., and Harrison, S. (2007). An atomic model of enhanceosome structure in the vicinity of DNA. Cell 129, 1111-1123. doi: 10.1016/j.cell.2007.05.019

Parker, D., Cohen, T. S., Alhede, M., Harfenist, B. S., Martin, F. J., and Prince, A. (2012). Induction of type I interferon signaling by Pseudomonas aeruginosa is diminished in cystic fibrosis epithelial cells. Am. J. Respir. Cell Mol. Biol. 46, 6-13. doi: 10.1165/rcmb.2011-0080OC

Parker, D., Martin, F., Soong, G., Harfenist, B., Aguilar, J., Ratner, A., et al. (2011). Streptococcus pneumoniae DNA initiates type I interferon signaling in the respiratory tract. MBio 2:e00016-00011. doi: $10.1128 / \mathrm{mBio} .0$ 0016-11

Parker, D., Planet, P. J., Soong, G., Narechania, A., and Prince, A. (2014). Induction of type I interferon signaling determines the relative pathogenicity of Staphylococcus aureus strains. PLoS Pathog. 10:e1003951. doi: 10.1371/journal.ppat.1003951

Parker, D., and Prince, A. (2012). Staphylococcus aureus induces type I IFN signaling in dendritic cells via TLR9. J. Immunol. 189, 4040-4046. doi: 10.4049/jimmunol.1201055

Parvatiyar, K., Zhang, Z., Teles, R., Ouyang, S., Jiang, Y., Iyer, S., et al. (2012). DDX41 recognizes bacterial secondary messengers cyclic di-GMP and cyclic di-AMP to activate a type I interferon immune response. Nat. Immunol. 13, 1155-1161. doi: $10.1038 /$ ni. 2460 
Patel, A., Lee-Lewis, H., Hughes-Hanks, J., Lewis, C., and Anderson, D. (2012). Opposing roles for interferon regulatory factor-3 (IRF-3) and type I interferon signaling during plague. PLoS Pathog. 8:e1002817. doi: 10.1371/journal.ppat.1002817

Pechous, R., Sivaraman, V., Price, P., Stasulli, N., and Goldman, W. (2013). Early host cell targets of Yersinia pestis during primary pneumonic plague. PLoS Pathog. 9:e1003679. doi: 10.1371/journal.ppat.1003679

Peng, K., Broz, P., Jones, J., Joubert, L. M., and Monack, D. (2011). Elevated AIM2mediated pyroptosis triggered by hypercytotoxic Francisella mutant strains is attributed to increased intracellular bacteriolysis. Cell. Microbiol. 13, 1586-1600. doi: 10.1111/j.1462-5822.2011.01643.x

Peters, K., Dhariwala, M., Hughes-Hanks, J., Brown, C., and Anderson, D. (2013). Early apoptosis of macrophages modulated by injection of Yersinia pestis YopK promotes progression of primary pneumonic plague. PLoS Pathog. 9:e1003324. doi: 10.1371/journal.ppat.1003324

Philip, N., Dillon, C., Snyder, A., Fitzgerald, P., Wynosky-Dolfi, M., Zwack, E., et al. (2014). Caspase- 8 mediates caspase- 1 processing and innate immune defense in response to bacterial blockade of NF-кB and MAPK signaling. Proc. Natl. Acad. Sci. U.S.A. 111, 7385-7390. doi: 10.1073/pnas.1403252111

Pierini, R., Perret, M., Djebali, S., Juruj, C., Michallet, M., Förster, I., et al. (2013). ASC controls IFN- $\gamma$ levels in an IL-18-dependent manner in caspase1-deficient mice infected with Francisella novicida. J. Immunol. 191, 3847-3857. doi: 10.4049/jimmunol.1203326

Pinto, A., Ramos, H., Wu, X., Aggarwal, S., Shrestha, B., Gorman, M., et al. (2014). Deficient IFN signaling by myeloid cells leads to MAVS-dependent virus-induced sepsis. PLoS Pathog. 10:e1004086. doi: 10.1371/journal.ppat.10 04086

Plumlee, C., Lee, C., Berg, A., Decker, T., Shuman, H., and Schindler, C. (2009). Interferons direct an effective innate response to Legionella pneumophila infection. J. Biol. Chem. 284, 30058-30066. doi: 10.1074/jbc.M109.018283

Pollitzer, R. (1954). Plague. Geneva: World Health Organization.

Power, M. R., Li, B., Yamamoto, M., Akira, S., and Lin, T. J. (2007). A role of Toll-IL-1 receptor domain-containing adaptor-inducing IFN-beta in the host response to Pseudomonas aeruginosa lung infection in mice. J. Immunol. 178, 3170-3176. doi: 10.4049/jimmunol.178.5.3170

Price, P., Jin, J., and Goldman, W. (2012). Pulmonary infection by Yersinia pestis rapidly establishes a permissive environment for microbial proliferation. Proc. Natl. Acad. Sci. U.S.A. 109, 3083-3088. doi: 10.1073/pnas.11127 29109

Rayamajhi, M., Humann, J., Penheiter, K., Andreasen, K., and Lenz, L. (2010). Induction of IFN-ab enables Listeria monocytogenes to suppress macrophage activation by IFN-g. J. Exp. Med. 207, 327-337. doi: 10.1084/jem.20091746

Raymond, B., Young, J., Pallett, M., Endres, R., Clements, A., and Frankel, G. (2013). Subversion of trafficking, apoptosis, and innate immunity by type III secretion system effectors. Trends Microbiol. 21, 430-441. doi: 10.1016/j.tim.2013. 06.008

Rebeil, R., Ernst, R. K., Jarrett, C. O., Adams, K. N., Miller, S. I., and Hinnebusch, B. J. (2006). Characterization of late acyltransferase genes of Yersinia pestis and their role in temperature-dependent lipid a variation. J. Bacteriol. 188, 1381-1388. doi: 10.1128/JB.188.4.1381-1388.2006

Repasy, T., Lee, J., Marino, S., Martinez, N., Kirschner, D. E., Hendricks, G., et al. (2013). Intracellular bacillary burden reflects a burst size for Mycobacterium tuberculosis in vivo. PLoS Pathog. 9:e1003190. doi: 10.1371/journal.ppat.10 03190

Robinson, N., Mccomb, S., Mulligan, R., Dudani, R., Krishnan, L., and Sad, S. (2012). Type I interferon induces necroptosis in macrophages during infection with Salmonella enterica serovar typhimurium. Nat. Immunol. 13, 954-962. doi: 10.1038/ni.2397

Rosenberger, C., Scott, M., Gold, M., Hancock, R., and Finlay, B. (2000). Salmonella typhimurium infection and lipopolysaccharide stimulation induce similar changes in macrophage gene expression. J. Immunol. 164, 5894-5904. doi: 10.4049/jimmunol.164.11.5894

Rytkonen, A., Poh, J., Garmendia, J., Boyle, C., Thompson, A., Liu, M., et al. (2007). SseL, a Salmonella deubiquitinase required for macrophage killing and virulence. Proc. Natl. Acad. Sci. U.S.A. 104, 3502-3507. doi: 10.1073/pnas.06100 95104

Santos, R. (2014). Pathobiology of Salmonella, intestinal microbiota, and the host innate immune response. Front. Immunol. 5:252. doi: 10.3389/fimmu.2014.00252
Sato, M., Hata, N., Asagiri, M., Nakaya, T., Taniguchi, T., and Tanaka, N. (1998) Positive feedback regulation of type I IFN genes by the IFN-inducible transcription factor IRF-7. FEBS Lett. 441, 106-110. doi: 10.1016/S0014-5793(98)0 1514-2

Schmolke, M., Patel, J., De Castro, E., Sánchez-Aparicio, M., Uccellini, M., Miller, J., et al. (2014). RIG-I Detects mRNA of intracellular Salmonella enterica serovar typhimurium during bacterial infection. MBio 5:e01006-01014. doi: 10.1128/mBio.01006-14

Schnupf, P., and Portnoy, D. (2007). Listeriolysin O: a phagosome-specific lysin. Microbes Infect. 9, 1176-1187. doi: 10.1016/j.micinf.2007.05.005

Schoggins, J., and Rice, C. (2011). Interferon-stimulated genes and their antiviral effector functions. Curr. Opin. Virol. 1, 519-525. doi: 10.1016/j.coviro.2011.10.008

Schroder, K., and Tschopp, J. (2010). The inflammasomes. Cell 140, 821-832. doi: 10.1016/j.cell.2010.01.040

Schwartz, J., Barker, J., Kaufman, J., Fayram, D., Mccracken, J., and Allen, L. (2012). Francisella tularensis inhibits the intrinsic and extrinsic pathways to delay constitutive apoptosis and prolong human neutrophil lifespan. J. Immunol. 188, 3351-3363. doi: 10.4049/jimmunol.1102863

Shah, S., Bohsali, A., Ahlbrand, S., Srinivasan, L., Rathinam, V., Vogel, S., et al. (2013). Cutting edge: Mycobacterium tuberculosis but not nonvirulent mycobacteria inhibits IFN- $\beta$ and AIM2 inflammasome-dependent IL- $1 \beta$ production via its ESX-1 secretion system. J. Immunol. 191, 3514-3518. doi: 10.4049/jimmunol.1301331

Skyberg, J., Rollins, M., Samuel, J., Sutherland, M., Belisle, J., and Pascual, D. (2013). Interleukin-17 protects against the Francisella tularensis live vaccine strain but not against a virulent F. tularensis type A strain. Infect. Immun. 81, 3099-3105. doi: 10.1128/IAI.00203-13

Stark, G., Kerr, I., Williams, B., Silverman, R., and Schreiber, R. (1998). How cells respond to interferons. Ann. Rev. Biochem. 67, 227-264. doi: 10.1146/annurev.biochem.67.1.227

Sutterwala, F. S., Mijares, L. A., Li, L., Ogura, Y., Kazmierczak, B. I., and Flavell, R. A. (2007). Immune recognition of Pseudomonas aeruginosa mediated by the IPAF/NLRC4 inflammasome. J. Exp. Med. 204, 3235-3245. doi: 10.1084/jem.20071239

Sweet, C., Conlon, J., Golenbock, D., Goguen, J., and Silverman, N. (2007). YopJ targets TRAF proteins to inhibit TLR-mediated NF-kB, MAPK and IRF3 signal transduction. Cell. Microbiol. 9, 2700-2715. doi: 10.1111/j.1462-5822.2007.00990.x

Takeuchi, O., and Akira, S. (2010). Pattern recognition receptors and inflammation. Cell 140, 805-820. doi: 10.1016/j.cell.2010.01.022

Torres, D., Barrier, M., Bihl, F., Quesniaux, V., Maillet, I., Akira, S., et al. (2004). Tolllike receptor 2 is required for optimal control of Listeria monocytogenes infection. Infect. Immun. 72, 2131-2139. doi: 10.1128/IAI.72.4.2131-2139.2004

Valdimer, G., Weng, D., Paquette, S., Vanaja, S., Rathinam, V., Aune, M., et al. (2012). The NLRP12 inflammasome recognizes Yersinia pestis. Immunity 37, 96-107. doi: 10.1016/j.immuni.2012.07.006

Vega-Ramos, J., Alari-Pahissa, E., Del Valle, J., Carrasco-Marın, E., Esplugues, E., Borras, M., et al. (2010). CD69 limits early inflammatory diseases associated with immune response to Listeria monocytogenes infection. Immunol. Cell Biol. 88, 707-715. doi: 10.1038/icb.2010.62

Weigent, D. A., Huff, T. L., Peterson, J. W., Stanton, G. J., and Baron, S. (1986). Role of interferon in streptococcal infection in the mouse. Microb. Pathog. 1, 399-407. doi: 10.1016/0882-4010(86)90071-9

Weng, D., Marty-Roix, R., Ganesan, S., Proulx, M. K., Vladimer, G. I., Kaiser, W. J., et al. (2014). Caspase- 8 and RIP kinases regulate bacteria-induced innate immune responses and cell death. Proc. Natl. Acad. Sci. U.S.A. 111, 7391-7396. doi: 10.1073/pnas.1403477111

Winter, S., Thiennimitr, P., Winter, M., Butler, B., Huseby, D., Crawford, R., et al. (2010). Gut inflammation provides a respiratory electron acceptor for Salmonella. Nature 467, 426-429. doi: 10.1038/nature09415

Woodward, J., Iavarone, A., and Portnoy, D. (2010). c-di-AMP secreted by intracellular Listeria monocytogenes activates a host type I interferon response. Science 328, 1703-1705. doi: 10.1126/science.1189801

Wyant, T., Tanner, M., and Sztein, M. (1999). Salmonella typhi flagella are potent inducers of proinflammatory cytokine secretion by human monocytes. Infect. Immun. 67, 3619-3624.

Zauberman, A., Tidhar, A., Levy, Y., Bar-Haim, E., Halperin, G., Flashner, Y., et al. (2009). Yersinia pestis endowed with increased cytotoxicity is avirulent in a 
bubonic plague model and induces rapid protection against pneumonic plague. PLoS ONE 4:e5938. doi: 10.1371/journal.pone.0005938

Zhang, Y., Romanov, G., and Bliska, J. (2011). Type III secretion systemdependent translocation of ectopically expressed Yop effectors into macrophages by intracellular Yersinia pseudotuberculosis. Infect. Immun. 79, 4322-4331. doi: 10.1128/IAI.05396-11

Zheng, Y., Lilo, S., Brodsky, I., Zhang, Y., Medzhitov, R., Marcu, K., et al. (2011). A Yersinia effector with enhanced inhibitory activity on the NF- $\kappa \mathrm{B}$ pathway activates the NLRP3/ASC/caspase-1 inflammasome in macrophages. PLoS Pathog. 7:e1002026. doi: 10.1371/journal.ppat.1002026

Zhou, H., Monack, D., Kayagaki, N., Wertz, I., Yin, J., Wolf, B., et al. (2005). Yersinia virulence factor YopJ acts as a deubiquitinase to inhibit NF-kappa B activation. $J$. Exp. Med. 202, 1327-1332. doi: 10.1084/jem.20051194

Zwaferink, H., Stockinger, S., Hazemi, P., Lemmens-Gruber, R., and Decker, T. (2008). IFN- $\beta$ increases Listeriolysin $\mathrm{O}$-induced membrane permeabilization and death of macrophages. J. Immunol. 180, 4116-4123. doi: 10.4049/jimmunol.180.6.4116
Conflict of Interest Statement: The authors declare that the research was conducted in the absence of any commercial or financial relationships that could be construed as a potential conflict of interest.

Received: 24 June 2014; accepted: 30 September 2014; published online: 28 October 2014.

Citation: Dhariwala MO and Anderson DM (2014) Bacterial programming of host responses: coordination between type I interferon and cell death. Front. Microbiol. 5:545. doi: 10.3389/fmicb.2014.00545

This article was submitted to Microbial Immunology, a section of the journal Frontiers in Microbiology.

Copyright $($ C 2014 Dhariwala and Anderson. This is an open-access article distributed under the terms of the Creative Commons Attribution License (CC BY). The use, distribution or reproduction in other forums is permitted, provided the original author(s) or licensor are credited and that the original publication in this journal is cited, in accordance with accepted academic practice. No use, distribution or reproduction is permitted which does not comply with these terms. 